\title{
The Efficiency of Mergers and Acquisitions in Malaysia Based Telecommunication Companies
}

\author{
Wan Anisabanum Binti Salleh ${ }^{1}$, Wan Mansor Wan Mahmood ${ }^{1}$, Fadzlan Sufian ${ }^{2}$, Ernie Melini Mohd Jamarudi ${ }^{3}$, \\ Gopala Krishnan Sekharan $\mathrm{Nair}^{4} \&$ Suraya Ahmad ${ }^{1}$ \\ ${ }^{1}$ Business \& Management Faculty, Universiti Teknologi MARA (UiTM), Dungun Campus, Dungun, Malaysia \\ ${ }^{2}$ International Islamic University, Malaysia \\ ${ }^{3}$ Faculty of Law, Universiti Teknologi MARA (UiTM), Dungun Campus, Dungun, Malaysia \\ ${ }^{4}$ Academy of Language Studies, Universiti Teknologi MARA (UiTM), Dungun Campus, Dungun, Malaysia \\ Correspondence: Wan Anisabanum Binti Salleh, Business \& Management Faculty, Universiti Teknologi MARA \\ (UiTM), Dungun Campus, 23000 Dungun, Terengganu, Malaysia. E-mail: wananisa@tganu.uitm.edu.my
}

Received: December 5, 2012 Accepted: December 24, 2012 Online Published: January 28, 2013

doi:10.5539/ass.v9n2p12

URL: http://dx.doi.org/10.5539/ass.v9n2p12

We thank the Ministry of Education of Malaysia and the Research Management Institute, University Technology MARA for the Fundamental Research Grant Scheme to which the fund is used for the purpose of this research.

\begin{abstract}
This paper analyses the technical efficiencies (TE) of total asset model, current asset model and expense model of the mergers and acquisition (M\&A) activities in Malaysia based telecommunication companies. For the purpose of this research, a two-stage analysis has been used. For the first stage, a CCR model is used to calculate the technical efficiency of individual companies during the period 2005-2010 and the multiple regression analysis is adopted in the second stage to examine factors such as intensity of acquisitions, sequence of acquisitions and size which influence the efficiency of the companies. As a result of the regression analysis, there is an existence of significant relationship which is of negative value between sequence of acquisitions and TE in both total asset model and current asset model. Further findings also showed that there is a significant relationship between size and TE in the current asset model and in the total asset model but the former holds a positive relationship while the latter has a negative relationship. Based on the regression analysis, none of the said factors above could explain the variation in TE in the expense model. At the end of this research, it is recommended that a further study should be done on this area by including additional variables namely the existence of the government linked corporations (GLCs) among the telecommunication companies and role of regulatory as they might also affect companies which are involved in M\&A.
\end{abstract}

Keywords: mergers and acquisitions intensity and sequence, data envelopment analysis, telecommunication, Malaysia

\section{Introduction}

In a technology-intensive and globally competitive atmosphere, it is not rare for companies such as the telecommunication companies to get involve in mergers and acquisitions (here in after M\&A). It has become a business tradition that M\&A activities are one of the routes to enhance relative technical efficiency in an effort to increase the overall efficiency which would later be translated into increase revenue.

Due to the fact that telecommunication sector holds the highest involvement in M\&A globally (Buckley,2010), this paper examined the efficiency of public listed telecommunication companies based in Malaysia of over a six-year period i.e. from 2005 to 2010. 
Table 1. List of Malaysia based telecommunication companies

\begin{tabular}{llc}
\hline NO. & \multicolumn{1}{c}{ COMPANY } & INVOLVEMENT IN M\&A \\
\hline $\mathbf{1 .}$ & TELEKOM MALAYSIA BERHAD & YES \\
$\mathbf{2 .}$ & DIGI.COM BERHAD & NO \\
$\mathbf{3 .}$ & TIME DOTCOM BERHAD & YES \\
$\mathbf{4 .}$ & AXIATA GROUP BERHAD & YES \\
$\mathbf{5 .}$ & REDTONE INTERNATIONAL BERHAD & YES \\
$\mathbf{6 .}$ & GREEN PACKET BERHAD & YES
\end{tabular}

Among all these companies stated above (refer to Table 1), only DiGi.Com Berhad has not take part in M\&A and has been chosen to be the comparative yardstick to those which involved in M\&A. Therefore, there are five companies have been involved in M\&A for sample of this study. Nasioncom Holdings Berhad and XOX Berhad are excluded from the sample because there is insufficient data for the purpose of this study.

In achieving the first objective of this study, the researchers decided to use the total asset model, the current asset model and the expense model to evaluate and investigate the types of technical efficiency achieved among the merged companies. Then the relative technical efficiency is computed against the total revenue earned.

Generally, it is accepted that a firm is deemed to have greater relative technical efficiency as compared to its peers, if it can generate the same output as the other competing firms even though the input may be less than other competing firms. A similar situation could happen to a firm which can generate more output than the other competing firms even though the input is the same among each other. If a firm has lesser quantum of input comparing with the other competing firms, it may still have high relative technical efficiency provided that it is able to produce greater output than others.

However, in many cases the technical efficiency achieved did not bring about commensurate revenue increase on account of indiscriminate intensity and sequencing of M\&A. Intensity denotes the number of M\&A in any particular year whereas; sequencing refers to the accumulated number of M\&A over any given period of years. Hence, this brought to the second objective of this study which is to evaluate the impact of acquisitions intensity and acquisitions sequencing in achieving the technical efficiency. The contribution of size of the acquiring companies towards technical efficiency is also considered.

Based on Singh and Mogla (2008), Indian firms that merged declined in profitability over the period of the operation while Kumar (2009) also agrees that the profitability of the acquired companies showed no improvement when comparing with pre-merger values. Certain companies such as Wolter Kluwer which is known as major multinational publishing house suffered loss after merging and the reasons are due to failure to integrate the hundred-plus acquisitions it has engaged in over the decades [(NRC Handelsblad, 2003) as cited in Barkema and Schijven (2008)].

Other scholar namely Dumon (2009) opines that new companies may appreciate in value if the merger goes well leading to investors expected synergies being realized. The author further opines that it cannot be denied that there is still fear of over estimation of synergies and lack of understanding of the acquired firm's business. From his findings, when this situation occurs, it is likely for the shareholder value being jeopardized and the company's stock price would decline.

Additionally, Kusewitt (1985) who studies on the importance of sequencing stated that an acquisition is rarely an isolated event but merely one part of an overarching sequence of acquisitions cumulatively targeted at executing a corporate strategy. Often, most researchers who have investigated acquisitions have a tendency to view the acquisition as a distinct isolated occurrence when in fact it may be one part of a series of events. They believe that when the acquirer is considered as the unit of analysis, strategy is conceptualized as a sequence of decisions and actions taken one at a time, over a period of years (Fredrickson \& Mitchell, 1984). Consequently, a sequence of acquisitions leads to the collection of organizational inefficiencies.

This study proposes that acquisitions can be beneficial if the sequence and intensity of integration is properly strategized.

\section{Literature Review}

This section outlines the study of other scholars on companies which have involved in mergers and acquisitions (here in after M\&A). Although this paper concentrates only on telecommunication companies, it does not 
abandon other sectors from being discussed here as they are also pertinent to M\&A activities. The following sections would also touch on the application of data envelopment analysis (here in after DEA) in measuring the relative efficiency among peer entities and the regression analysis which has been used in the second stage of this research. In addition to the discussion in this section are the studies on acquisitions intensity and sequencing as well as the size of acquiring companies.

\subsection{Measuring the Relative Efficiency amongst Peer Entities Using DEA}

The main aim of having M\&A is to gain a greater relative efficiency through the infusion of additional input. Many scholars agree that less efficient firms have less stable performance in comparison with more efficient firms which would guarantee a more stable performance. This has been proven in a study made by Gahan and Porter (1999) that there is evidence showing efficient firms gain higher return than less efficient firms within the same industry. Nonetheless, in measuring the relative efficiency amongst peer entities as what have been done by Gahan and Porter (supra), vast scholars prefer to use DEA which is defined by Charnes et.al (1978) as a mathematical programming approach; useful when the relative efficiency of similar establishment is measured.

The application of DEA is frequently applied to evaluate the efficiency of public and non-profit organizations such as hospitals (Vera \& Kuntz, 2007; Kuntz, Scholtes \& Vera, 2007) or police forces (Thanassoulis, 1995). DEA is also being used for benchmarking in various studies such as evaluating the Arab Banks (Mostafa, 2007), third-party logistics providers (Min \& Joo, 2006), nursing homes (Duffy et. al. 2006) and airports (Graham, 2005). DEA application can be seen in measuring any efficiency gain or loss as the consequence of M\&A (Sufian, 2006).

Technical efficiency is one of the selected applications of DEA to measure the efficiency of companies which involved in M\&A. There are several scholars rely on technical efficiency as one of the criteria for example Sufian (2006) has used technical efficiency in evaluating the Singapore's banking group; Sufian \& Habibullah (2009) used to evaluate the efficiency of Malaysian banks during the period of $1997-2003$; Kwon et.al (2008) has studied the efficiency of US wireless mobile communication companies during the period of 2002-2005; Sufian (2004) has evaluated the efficiency of domestic incorporated Malaysian commercial banks before, during and after the year of merger and Wu (2008) has studied the efficiency of Australian based banks during the period of 1983-2001 focusing on the 'four pillars' policy that preventing mergers among the four major banks.

In evaluating the efficiency of companies which involved in M\&A, it is often to measure those companies against the companies which do not take part in M\&A with the purpose to account for the general industry trends in efficiency. There are selected findings for measuring relative efficiencies which have a direct bearing on this study and these include Sufian \& Hasbibullah's (2009) who found that banks involved in mergers were less cost efficient than control groups of non-merging banks. Meanwhile, Wu (2008) found that mergers among banks usually result in much lower efficiency in the overall banking sector. Kwon et al. (2008) stated that wireless communication companies showed the lowest efficiency scores in the year of merger as compared to non-merging companies.

Although there is vast usage of DEA, little has been written on efficiency measurement in the telecommunication industry as evidenced by Zhu (2004), Cooper et.al (2001), Uri (2001), Majumdar (1998) and Majumdar \& Chang (1996). However, Majumdar et.al (2010) does looked at the impact of mergers on the efficiency of telecommunication companies and Kwon et.al (supra) has analysed the trend of the technical efficiency of wireless communication companies which involved in mergers. The analysing of the acquisitions intensity and sequencing pertaining to the telecommunication companies in Malaysia by the authors of this paper is an extension to the techniques used by Kwon et.al (supra).

\subsection{The Regression Analysis as a Second Stage Analysis}

In many cases of carrying out the efficiency analysis, Holf (2007) explains that the ordinary least squares (here in after OLS) may actually replace Tobit estimation as a sufficient second stage analysis following the DEA model. McDonald (2009) states that Tobit estimation is the most suitable for dependant variable data which is obtained by a censoring data generating process but it is not viable when the data is fractional in nature whereas the OLS is an unbiased and consistent estimator. Moreover, although there may be cases where a limit can be fixed at zero in many applications, it is unlikely to have zero efficiency scores and even scores close to zero is in fact rare (McDonald, supra).

Since the efficiency score data for this study is neither censors nor corner solution data, the OLS is preferred to analyse the size of acquiring firms and also the intensity as well as the sequencing of acquisition. 


\subsection{The Size of Acquiring Firm}

Synergies can be created through economies of scale and the combination of companies can create efficiency through size (Seth, 1990). Hence, by improving the resource allocation these combined companies are expected to promote the overall economic gains (Wan Mahmood \& Mohammad, 2007). Furthermore, the combination of companies normally achieves greater efficiency in many departments such as marketing, production and transportation (Wan Mahmood \& Mohammad, supra). Therefore, from these views, this study considers size as the important variable affecting the relative efficiency in the fast moving industry.

\subsection{The Intensity and Sequence of Acquisitions}

A firm that has managed to create well developed routine during its acquisition process is said to be effectively integrate most of its acquisition within 100 days (Ashkenas et.al. 1998). This is evidenced in WU (2008) where highly acquisitive banks are found to perform better than other less acquisitive banks which suggesting that banks can learn from multiple mergers and indeed improve their post-merger efficiencies. In Barkema \& Schijven (2008), it is stated that the higher the acquisition intensity, the less time for an acquirer to search and implement for an effective course of action before engaging in the next acquisition. Thus, the acquirer performance would decline.

For the purpose of this study, the acquisitions intensity denotes the number of acquisitions in any particular year while the sequence of acquisitions refers to the accumulated number of acquisition over any given number of years.

Generally, M\&A tendencies are based on the behavioural theory which focuses on the decision making at the operating level and its applicability on strategic issues (Cyert \& March, 1963). On the other hand, classic behavioural theory postulates that a search for remedies is initiated in the event of failure or prediction of failure to meet a goal (Cyert \& March, supra).

As firms repeat a task over a period of time, the search process is triggered by that task and becomes routine in nature (Levitt \& March, 1988). However, most of the underlying sub-activities may be quite similar across deals which are performed by the same individuals or departments as pondered by Herbert et.al. (2005). The examples of sub-activities are identifying, screening, deciding on an acquisition target, negotiating the purchase and managing the integration process through integration teams.

By taking consideration of the above views, this study is done by taking into account the impact of acquisitions intensity and sequence undergone by the recent companies using the year-by-year trajectories.

\section{Research Methodology}

As mentioned above, this study would focus on six public listed Malaysia based telecommunication companies which have involved in M\&A except for one namely Digi.Com Berhad. The reason for choosing the public listed companies is because of the difficulties in getting data from the non-listed companies in which many of the non-listed companies have strict regulations on confidentiality due to intense competition. The impact of size intensity as well as the sequence of acquisitions on technical efficiency will be evaluated by using the total asset model, the current asset model and the expense model performance over a period of six years i.e. 2005-2010.

The population comprises all public listed telecommunication companies based in Malaysia. From this population, a sample of six is chosen and derived from sources such as the Thomson Reuter and Bloomberg Business Week. The specific years of the companies' involvement in M\&A are ascertained. Besides that, the acquiring companies' annual balance sheet assets and income statements from data stream are also been taken and scrutinized where the results are used to ascertain the efficiency.

This study intends to provide a broad view of the effects of acquisitions which involve two stages of analyses. In the first stage, the DEA has been applied by using the CCR model to calculate the technical efficiency using the total asset, current asset and expense model. The second stage involves the regression analysis to examine the influence of the characteristics such as acquisition intensity, sequence of acquisitions and size of the acquiring companies on the efficiency of the companies.

The purpose of the DEA model being used is to analyse the trends in technical efficiency. The pioneer of this model is Charnes et.al. (1978) and this model is also famously known by other names like Charnes, Cooper and Rhodes model i.e. CCR (the authors would refer to CCR throughout this study). The CCR model is based on the premise of constant returns scale (here in after CRS) for the input and output (Mustafa, 2007). The current assets and expenses are favoured choices as compared to fixed assets since the formers are relatively easier to control (Kwon et.al, 2008). Hence, CCR-Input (CCR-I) oriented models are used for this study. For the total asset model 
that includes fixed assets, the CCR-output (CCR-O) oriented models are favoured as it enables freedom in output projections. Chen et. al. (2008) found that the DEA models enable researchers to objectively combine different inputs and outputs of various firms and convert into a single measure which will denote the overall organizational efficiency.

Following Kwon et. al. (2008), this study employs total assets, total current assets and total expenses as inputs. The inputs are paired with the output variable and annual revenue for analysis. The method in ascertaining the inputs and outputs by the means aforementioned can be justified by the existing literature which supports managerial analysis, multivariate analysis and simple ratio analysis (Emrouznejad \& De Witte, 2010). The managerial analysis takes into account the best inputs and outputs according to the entities while the multivariate analysis checks the multicolinearity between the different inputs and outputs (Emrouznejad \& De Witte, supra).

Table 2. Models and variables

\begin{tabular}{llcc}
\hline \multicolumn{1}{c}{ MODEL } & \multicolumn{1}{c}{ INPUT VARIABLE } & \multicolumn{1}{c}{$\begin{array}{c}\text { OUTPUT } \\
\text { VARIABLE }\end{array}$} \\
\hline TOTAL ASSET MODEL & \multicolumn{1}{c}{ Current assets; } & property, plant and equipment & Revenue \\
CURRENT ASSET MODEL & Cash; cash and short term investment; & accounts receivable & Revenue \\
EXPENSE MODEL & Depreciation, depletion and amortization; & operating expenses & Revenue \\
\hline
\end{tabular}

Table 2 shows the three models with input and output variables. For the total asset model, the asset utilization of the companies are examined by dividing total assets into two categories which are current assets being in one category while property, plant and equipment being the other category. The total asset model is rather similar to return on assets (ROA) known as an orthodox profitability measure in finance. However, DEA can show the impact of each individual asset category on profitability unlike ROA.

The current asset model is used to determine efficiencies on working capital in comparison with revenue. Cash, cash and short term investment and accounts receivable as shown in Table 2 above are the usual working capital and the prudent management of which would affect the companies' cash flow. Therefore, injudicious current assets management may result winding up of companies.

The purpose of expense model is to show the cost management efficiency by dividing expense model into two categories namely depreciation, depletion and amortization being grouped in one category while operating expenses as the other category. In utilising the assets, cost management is vital to the companies' profitability. An efficient cost management that couple with asset utilization allowing companies to gain profit in the market.

Based on Barkema \& Schijven (2008), when the acquisition intensity is higher, the acquirer would have less time to search and plan winning strategies before engaging in the next acquisition which reducing the acquirer performance.

By relying on the available corpus of data, it can be hypothesized that the higher acquisition intensity and sequencing of acquiring firms may result lower technical efficiency. Hence, the hypothesis can be summarised as follows:-

H1: The higher the acquisitions intensity of acquiring firms, the lower the technical efficiency.

Hla: The higher the acquisitions intensity of acquiring firms, the lower the technical efficiency under the total asset model.

$H 1 b$ : The higher the acquisitions intensity of acquiring firms, the lower the technical efficiency under the current asset model.

H1c: The higher the acquisitions intensity of acquiring firms, the lower the technical efficiency under the expense model.

H2: $\quad$ The higher the sequence of acquiring firms, the lower the technical efficiency.

$H 2 a$ : The higher the sequence of acquiring firms, the lower the technical efficiency under the total asset model.

$H 2 b$ : The higher the sequence of acquiring firms, the lower the technical efficiency under the current asset model.

H2c: The higher the sequence of acquiring firms, the lower the technical efficiency under the expense model. 
Lubatkin (1983) has introduced the concept of market power as another source of synergy; suggesting that the company's ability to dictate prices and exert market power is achieved by size. For example in Azofra et. al. (2008) and Wooi et. al. (2009) have determined the size of the companies by computing the logarithm of the total asset. Another finding by Lo \& Lu (2006) shows that size does not matter and big-sized entities are generally more efficient than the small-sized ones. Thus, the following hypothesis regarding the relationship between the technical efficiency and size of firms can be formed:-

H3: $\quad$ The size of acquiring firms are positively related to the technical efficiency

H3a: The size of acquiring firms is positively related to the technical efficiency under the total asset model.

$H 3 b$ : The size of acquiring firms is positively related to the technical efficiency under the current asset model.

H3c: The size of acquiring firms is positively related to the technical efficiency under the expense model.

In computing the technical efficiency, the linear programming model can be solved with the ordinary linear reprogramming software (Kwon et. al. 2008). Nevertheless, this can save time and effort of other DEA solvers (Kwon et. al. supra).

The followings are the empirical model specification in the form of a fractional programming problem inspired by Charnes et. al. (1978):-

$$
\max _{0}=\frac{\sum_{f=1}^{F} U_{f}^{0} Y_{f}^{0}}{\sum_{i=1}^{T} V_{i}^{0} X_{i}^{0}}
$$

subject to

$$
\begin{gathered}
\frac{\sum_{f=1}^{F} U_{f}^{0} Y_{f}^{0}}{\sum_{i=1}^{I} V_{i}^{0} X_{i}^{0}} \leq 1 \text { for all } k \\
U_{f}^{0}, V_{i}^{0} \geq \delta \quad \text { for all } f, i
\end{gathered}
$$

$E 0$ is the efficiency score for the base DMU 0

Yfk is the observed quantity of output $f$ generated by unit $\mathrm{k}=1,2 \ldots \mathrm{N}$

$X i k$ is the observed quantity of input $i$ by unit $k=1,2, \ldots \mathrm{N}$

$U_{f}^{0}$ is the computed weight given to output $f$ by the base unit 0

$V_{i}^{0}$ is the computed weight given to input $i$ by the base unit 0

$\delta$ is a very small positive number

In order to appraise efficiency, the above equation is modified into the usual components of a liner programming equation. In the CCR multiplier DEA models, the denominator is fixed as a constant whereas the numerator is maximised.

$$
\begin{gathered}
E_{0}=\sum_{f=1}^{F} U_{f}^{0} Y_{f}^{0} \text { subject to } \sum_{i=1}^{I} V_{i}^{0} X_{i}^{0}=1 \\
\sum_{f=1}^{F} U_{f}^{0} Y_{f}^{0}-\sum_{i=1}^{I} V_{i}^{0} X_{i}^{0} \leq 0 \\
U_{f}^{0}, V_{i}^{0} \geq \delta
\end{gathered}
$$

\section{Findings}

\subsection{Finding from Data Envelopment Analysis}

Every year, the companies are treated as independent Decision Making Unit (here in after DMU) and thus, the six companies chosen in this study for the period of six years representing 36 DMU for each individual company 
model.

Table 3. Technical efficiency (CCR efficiency scores)

\begin{tabular}{|c|c|c|c|c|c|c|c|}
\hline \multirow{2}{*}{ MODEL } & \multirow[b]{2}{*}{ COMPANIES } & \multicolumn{6}{|c|}{ YEAR } \\
\hline & & 2005 & 2006 & 2007 & 2008 & 2009 & 2010 \\
\hline \multirow{6}{*}{$\begin{array}{c}\text { Total Asset } \\
\text { Model }\end{array}$} & TELEKOM & 0.651 & 0.583 & 0.431 & 0.318 & 0.369 & 0.352 \\
\hline & TIME & 0.715 & 0.946 & 1.000 & 1.000 & 1.000 & 1.000 \\
\hline & DIGI & 1.000 & 1.000 & 1.000 & 1.000 & 1.000 & 1.000 \\
\hline & AXIATA & 0.260 & 1.000 & 0.732 & 0.432 & 0.631 & 0.539 \\
\hline & REDTONE & 1.000 & 1.000 & 1.000 & 1.000 & 0.833 & 0.638 \\
\hline & GREEN PACKET & 1.000 & 1.000 & 0.579 & 0.131 & 0.218 & 0.379 \\
\hline \multirow{6}{*}{$\begin{array}{c}\text { Current } \\
\text { Asset } \\
\text { Model }\end{array}$} & TELEKOM & 0.766 & 0.727 & 0.519 & 0.259 & 0.244 & 0.371 \\
\hline & TIME & 1.000 & 0.540 & 0.280 & 0.152 & 0.585 & 0.917 \\
\hline & DIGI & 1.000 & 1.000 & 1.000 & 1.000 & 1.000 & 1.000 \\
\hline & AXIATA & 0.530 & 1.000 & 0.964 & 0.664 & 0.772 & 0.763 \\
\hline & REDTONE & 1.000 & 0.513 & 0.526 & 0.363 & 0.263 & 0.235 \\
\hline & GREEN PACKET & 0.222 & 0.083 & 0.104 & 0.094 & 0.133 & 0.363 \\
\hline \multirow{6}{*}{$\begin{array}{c}\text { Expense } \\
\text { Model }\end{array}$} & TELEKOM & 0.325 & 0.699 & 0.824 & 0.738 & 0.801 & 0.779 \\
\hline & TIME & 0.198 & 0.342 & 0.444 & 0.155 & 0.785 & 0.845 \\
\hline & DIGI & 0.380 & 0.749 & 1.000 & 1.000 & 1.000 & 1.000 \\
\hline & AXIATA & 0.490 & 0.744 & 0.815 & 0.831 & 0.915 & 0.969 \\
\hline & REDTONE & 1.000 & 0.822 & 1.000 & 1.000 & 1.000 & 1.000 \\
\hline & GREEN PACKET & 1.000 & 1.000 & 1.000 & 0.547 & 0.602 & 0.949 \\
\hline
\end{tabular}

Note: The input and output-oriented TE score reported by DEAP varies between zero and one.

Table 4. Intensity and sequence of acquisitions

\begin{tabular}{llcccccc}
\hline COMPANIES & & $\mathbf{2 0 0 5}$ & $\mathbf{2 0 0 6}$ & $\mathbf{2 0 0 7}$ & $\mathbf{2 0 0 8}$ & $\mathbf{2 0 0 9}$ & $\mathbf{2 0 1 0}$ \\
\hline TELEKOM & Intensity & 1 & 5 & 4 & 2 & 2 & 0 \\
\multirow{2}{*}{ TIME } & Sequence & 1 & 6 & 10 & 12 & 14 & 14 \\
\multirow{2}{*}{ DIGI } & Intensity & 0 & 0 & 1 & 0 & 0 & 0 \\
& Sequence & 0 & 0 & 1 & 1 & 1 & 1 \\
\multirow{2}{*}{ AXIATA } & Intensity & 0 & 0 & 0 & 0 & 0 & 0 \\
\multirow{2}{*}{ REDTONE } & Sequence & 0 & 0 & 0 & 0 & 0 & 0 \\
& Intensity & 0 & 0 & 0 & 0 & 1 & 0 \\
GREEN & Sequence & 0 & 0 & 0 & 0 & 1 & 1 \\
PACKET & Intensity & 4 & 0 & 0 & 0 & 0 & 0 \\
& Sequence & 4 & 4 & 4 & 4 & 4 & 4 \\
\hline
\end{tabular}

Source: Thomson Reuter

Table 3 above shows the summary of efficiency scores of three different models and Table 4 shows the number of acquisitions for each company throughout the period.

In the total asset model, seventeen DMUs were found to be $100 \%$ efficient; Time in 2007 to 2010, Digi in 2005 to 2010, Axiata in 2006, Redtone in 2005 to 2008 and Green packet in 2005 to 2006. Whereas in the current asset model, there were nine DMUs which were $100 \%$ efficient, such as Time in 2005, Digi in 2005-2010, 
Axiata in 2006 and Redtone in 2005. However, in the expense model, only twelve DMUs were $100 \%$ efficient, namely, Digi in 2007 to 2010, Redtone in 2005 and again from 2007 to 2010 while Green packet in 2005 to 2007.

Telekom which engaged in acquisitions every year from 2005 to 2009 has the highest sequence of acquisitions. It also engaged in high intensity acquisitions in 2006 and 2007, five in 2006 and four in 2007. Despite the magnitude of its acquisitions, Telekom showed a decreasing trend in the total asset model in 2005 to 2008, and increased briefly in 2009 at a low rate and decreased again in 2010 at an equally low rate, thus displaying a prominent decreasing trend overall. As for the current asset model, Telekom also showed a decreasing trend in 2005 to 2009 but later recovered briefly in 2010 but still at a very low efficiency score. Whereas in the expense model, the efficiency scores of Telekom from 2007 to 2010 were consistent but not high enough to be substantial. Telekom needs to re-evaluate and reformulate its strategies following acquisitions in order to boost its efficiency scores.

Green Packet is another company studied which was also involved in the sequence of acquisitions. It was involved in acquisition's every year from 2006 to 2009. When evaluated using the total asset model, Green Packet was found to have achieved $100 \%$ score efficiencies for the duration 2005 to 2006, barely a year after the high intensity acquisition's in 2006, the efficiency plunged to $57.9 \%$ in 2007 and continued to decrease till 2009 , showing only a low rate increased in 2010. However, when Green Packet was viewed using the expenses model, it showed consistent $100 \%$ efficiencies scores from 2005 to 2007, however there was also the plunge in 2008 where the efficiency scores took a more than $50 \%$ dip. Nonetheless, the companies showed a recovery in efficiency scores in 2009 which continued to 2010 registering a remarkable turnaround. Thus, Green Packet should make every effort to improve current asset and total asset utilization to remain competitive.

Time was another company studied, it was only involved in a single acquisition activity in 2007 during which it demonstrated consistently high-efficiency scores when evaluated using total asset model. When the current asset utilization and cost efficiency were considered, Time declined in efficiency in 2008 but improved in 2009 and was able to return a satisfactory efficiency score in 2010. Thus, it managed to recover in two years after the acquisition in 2007.

Digi is one other telecommunication company that was studied. Out of the sample of six companies, only Digi did not get involved in any acquisition. Nevertheless it always displayed a positive trend. Its efficiency scores in the total asset model and current asset model are very high at $100 \%$ and consistent throughout the observation period. However when the expense model was used, Digi appeared to have improved from a low rate from 2005 to 2006. The improvement peaked at $100 \%$ in 2007 to 2010 .

When it comes to the company Axiata, the efficiency scores in the total asset model and expense model increased in 2009, that is the year in which it got involved in a single acquisition, however in 2010 the efficiency scores of the total asset model decreased, nonetheless the scores are still higher than before the acquisition took place. As the observation period ended in 2010, we are unable to say whether Axiata completely recovered from the decrease exhibited in its total asset utilization in 2010. Meanwhile the score in expense model shows increasing trend throughout the observation period.

As for Redtone, the efficiency scores in the all the three models was $100 \%$ during the multiple acquisitions in 2005. However, a year after acquisitions, in 2006, $100 \%$ efficiency was only shown using the total asset model. In fact in the total asset model, the 100\% efficiency scores continued until 2008, decreasing in 2009 and further decreasing in 2010. When using the current asset model, the efficiency scores of Redtone was only $100 \%$ in 2005 , the year of M\&As. In stark contrast, in 2006, only a year after acquisitions, the efficiency scores plunged by nearly $50 \%$, increasing only slightly in 2007 but further decreasing in 2008 and 2009 and finally ending with pathetically low efficiency scores in 2010 . However, Redtone shows perfect score throughout the observation period except in 2006. Redtone should make strenuous efforts to improve current asset and total asset utilization in order to remain competitive in the market.

\subsection{The Regression Result}

The regression analysis has been carried out in this study involving three different independent variables namely size, acquisitions intensity and sequence of acquisitions. 
Table 5. Result of model summary and ANOVA (regression analysis)

\begin{tabular}{lccc}
\hline \multicolumn{1}{c}{ MODEL } & Model Summary $^{\mathbf{b}}$ & ANOVA $^{\mathbf{b}}$ & \\
\hline & Adjusted R Square & F & Sig. \\
Total Asset Model & .574 & 16.724 & $.000^{\mathrm{a}}$ \\
Current Asset Model & .443 & 10.288 & $.000^{\mathrm{a}}$ \\
Expense Model & .019 & 1.222 & $.318^{\mathrm{a}}$ \\
\hline
\end{tabular}

a. Predictors: (Constant), $M \& A$ experience, Size, $M \& A$ intensity, Age

b. Dependent Variable: TE

Table 5 shows the result of regression analysis. The results shows that the total asset model and current asset model registered values of $57.4 \%$ and $44.3 \%$ variance in TE respectively. Therefore, the total asset model and current asset model can be considered viable for examining the effect of the variance of the three independent variables on TE.

However, expense model only registered a value of $1.9 \%$ variance in Technical efficiency (TE) when it was subjected to the test. Thus, it is a non robust model and will not be able adequately explain the effect of variances caused by size, acquisitions intensity and sequence of acquisitions on TE.

\subsection{Hypothesis Testing}

The relevant coefficient values are shown in Table 6 below:-

Table 6. Result of coefficients ${ }^{\mathrm{a}}$ (regression analysis)

\begin{tabular}{llccc}
\hline & MODEL & \multicolumn{3}{c}{ Standard Coefficients } \\
\hline \multirow{2}{*}{ Total Asset Model } & & Beta & $\mathrm{t}$ & \multicolumn{1}{c}{ Sig } \\
& (Constant) & & 7.326 & .000 \\
& Size & -.398 & -3.593 & .001 \\
& Intensity of acquisitions & .127 & 1.027 & .312 \\
& Sequence of acquisitions & -.724 & -5.868 & .000 \\
& (Constant) & & -.335 & .740 \\
& Size & .353 & 2.786 & .009 \\
& Intensity of acquisitions & -.014 & -.096 & .924 \\
& Sequence of acquisitions & -.601 & -4.266 & .000 \\
\hline
\end{tabular}

a. Dependent Variable: TE

b. Expense model is not presented in the table because it did not explain the effect of variances caused by size, intensity of a acquisitions and sequence of acquisitions on TE.

In testing $H l a$, the coefficient of acquisitions intensity under total asset model obtained is positive and insignificant ( $p>0.1$ ). Thus, the relationship is weak. Whereas in testing $H 1 b$, the coefficient of acquisitions intensity under current asset model obtained is negative and insignificant $(\mathrm{p}>0.1)$. Hence, the relationship is weak.

In the total asset model, sequence of acquisitions negatively influences TE. It is highly significant $(\mathrm{p}<0.001)$. The higher the sequence of acquisitions, the lower TE in the total asset model. Thus, $H 2 a$ is strongly supported. As with the total asset model, the current asset model also showed lowered TE with higher M\&A sequence of acquiring firms. The relationship is negative and highly significant $(\mathrm{p}<0.001)$. Therefore, $H 2 b$ is strongly supported.

In the total asset model, size was found to have a significant $(\mathrm{p}=0.001)$ but negative relationship with TE. Meaning that the bigger the size, the lower will be the TE. Thus, $\boldsymbol{H 3 a}$ is strongly supported. Whereas in the current asset model, size was found to have a positive relationship with TE. The relationship is significant $(p<0.05)$. Meaning a bigger size would result in an increase in TE. However, the finding is opposite the hypothesis claim about the effects in TE in the current asset model. Hence, $\boldsymbol{H} \mathbf{3} \boldsymbol{b}$ is partially supported. 


\section{Conclusion and Recommendations}

This study aims to analyze the technical efficiency (TE) trends of telecommunication companies based in Malaysia which have recently been actively involved in M\&As. Attempt has been made to measure the impact of size, acquisitions intensity and sequencing on the TE under three models, namely the total asset model, the current asset model and the expense model.

DEA enables one to obtain relative efficiency scores of the individual units so that managers can be alerted to specific sources of inefficiency. Such knowledge is needed so that the acquisitions intensity and sequencing would be strategized such that the public listed companies involved would be able to make the most efficient use of total assets and current asset.

The study of the firms in the sample that engaged in both intensity and sequence of acquisitions over the six-year study period, shows that the asset efficiency of acquirers tend to decrease. Essentially it was found that the contribution of particular acquisitions to an acquirer's performance depends on the manner of acquisitions intensity and sequence. A high sequence of acquisitions appeared to gradually decrease the efficiency of assets in contrast to situations where there was only single acquisition. Furthermore, this study indicated that firms need to strike a balance between acquisitions intensity and sequence of acquisitions.

If the sequence of acquisitions results in lower efficiency then the organization should space out the acquisitions over a certain period of time, or delay subsequent acquisitions. This would enable the organization to resolve any inefficiency or prevent the inefficiency from becoming worse. Barkema \& Schijven (2008) suggested that time interval between acquisitions can be increased to lower intensity and increase the firms performance.

The multiple regression analysis found that the higher the sequence of acquisitions, the lower the TE in the total asset model and current asset model, it is parallel with Barkema \& Schijven (2008). Hence, this paper suggests that when a company is involved in a sequence of acquisitions, it needs to capitalize on the total asset model and current asset model in order to reduce relative assets or increase revenue or both to be efficient.

The effect of company size on TE in the current asset is similar to the findings in Lo \& Lu (2006) that larger companies are generally more efficient than the smaller sized ones. Wan Mahmood and Mohammad (2007) states that synergy happens when a combination of companies can create efficiency through managing size more efficiently and effectively after M\&A by utilizing scarce resources more appropriately. As for the total asset model, the findings of this study pertaining to the effect of company size on TE is opposite to the findings of Lo \& Lu (2006), but similar to Byard \& Cebenoyan (2007) that size was negatively related with relative production efficiency. This reason could be that smaller company may have benefited from the advantages of technological progress, (Azofra et. al. 2008).

The loophole of this study includes its relatively short period of observation and scarcity of data because most of the telecommunication companies involved in M\&As only recently undergo public listing in the Malaysian Bursa website. Redtone and Green Packet are listed in 2004 while Axiata in 2005. Notwithstanding to this loophole, the findings of this study still provide a valuable insight into the operating status of companies which would enable the formulation of a future approach towards strategic intensity and sequence of acquisitions so that higher relative efficiencies can be realized.

As a result of this study, it is recommended that a future research should be made by expanding the scope of study by including more telecommunication companies based in different countries and by entailing additional variables such as the prevailing economic climate as during periods of global financial recession, acquiring companies may inevitably experience decreased efficiency. Factors such as the existence of government linked corporations (GLC) among telecommunication companies as well as the role of regulatory can be taken into account. This is because both the GLCs and regulatory which governs M\&A generally might at least influence the telecommunication companies that involved in M\&A.

Therefore, with the emergence of this study it is hope that the findings and the recommendations made above would be significantly useful to the companies which are interested in acquisition intensity and sequencing.

\section{References}

Ashkenas, R. N., DeMonaco, L. J., \& Francis, S. C. (1998). Making the deal real: How GE Capital integrates acquisitions. Harvard Business Review, 76(1), 165-178.

Azofra, S. S., Olalla. M. G., \& Olmo, B. T. (2008). Size, target performance and European bank mergers and acquisitions. American Journal of Business, 23(1), 53-63. http://dx.doi.org/10.1108/19355181200800004 
Barkema, H. G., \& Schijven, M. (2008). Toward unlocking the full potential of acquisitions: The role of organizational restructuring. Academy of Management Journal, 51(4), 696-722.

Buckley, S. (2010). Telecom M\&A rises up in 2010. Fierce Telecom, 1-3.

Byard, D., \& Cebenoyan, F. (2007). Alternative evidence on financial analysts' use of financial statement information. Review of Accounting and Finance Journal, 6(4), 442-459. http://dx.doi.org/10.1108/14757700710835087

Charnes, A., Cooper, W. W. \& Rhodes, E. (1978). Measuring the efficiency of decision making units. European Journal of Operational Research, 2, 429-444. http://dx.doi.org/10.1016/0377-2217(78)90138-8

Chen, G. M., Firth, M., \& Zhang, W. W. (2008). The efficiency and profitability effects of China's modern enterprise restructuring programme. Asian Review of Accounting, 16(1), 74-91. http://dx.doi.org/10.1108/13217340810872481

Cooper, W., Park, K., \& Yu, G. (2001). An illustrative application of IDEA (imprecise data envelopment analysis) to a Korean mobile telecommunication company. Operations Research, 49(6), 807-820. http://dx.doi.org/10.1287/opre.49.6.807.10022

Cyert, R. M., \& March, J. G. (1963). A behavioral theory of the firm. Englewood Cliffs, NJ: Prentice Hall.

Duffy, J., Fitzsimmons, J., \& Jain, N. (2006). Identifying and studying 'best-performing' services; an application of DEA to long-term care. Benchmarking: An International Journal, 13(3), 232-251. http://dx.doi.org/10.1108/14635770610668767

Dumon, M. (2009). Biggest merger and acquisition disasters. Investopedia ULC, 1-18.

Emrouznejad, A., \& Witte, K. D. (2010). COOPER-framework: A unified process for non-parametric projects. European Journal of Operational Research, 207(3), 1573-1586. $\mathrm{http}: / / \mathrm{dx}$.doi.org/10.1016/j.ejor.2010.07.025

Fredrickson, J. W., \& Mitchell, T. R. (1984). Strategic decision processes: Comprehensiveness and performance in an industry with an unstable environment. Academy of Management Journal, 27, 399-423. http://dx.doi.org/10.2307/255932

Gahan, M. A., \& Porter, M. (1999). The persistence of shocks to profitability. The Review of Economics and Statistics, 81(1), 143-153. http://dx.doi.org/10.1162/003465399767923890

Graham, A. (2005). Airport benchmarking: a review of the current situation. Benchmarking: An International Journal, 12(2), 99-111. http://dx.doi.org/10.1108/14635770510593059

Hebert, L., Very, P., \& Beamish, P. W. (2005). Expatriation as a bridge over troubled water: A knowledge-based perspective applied to cross-border acquisitions. Organization Studies, 26, 1455-1476. http://dx.doi.org/10.1177/0170840605057067

Hoff, A. (2007). Second stage DEA: Comparison of approaches for modelling the DEA score. European Journal of Operational Research, 181, 425-435. http://dx.doi.org/10.1016/j.ejor.2006.05.019

Kumar, R. (2009). Post-merger Corporate Performance: An Indian Perspective. Journal of Management and Finance, 32(2), 145-157.

Kuntz, L., Scholtes, S., \& Vera, A. (2007). Incorporating Efficiency in Hospital Capacity Planning in Germany. European Journal of Health Economics, 8(3), 213-223. http://dx.doi.org/10.1007/s10198-006-0021-6

Kusewitt, J. B. (1985). An exploratory study of strategic acquisition factors relating to performance. Strategic Management Journal, 6, 151-169. http://dx.doi.org/10.1002/smj.4250060205

Kwon, H., Stoeberl, P. A., \& Joo, S. (2008). Measuring comparative efficiencies and merger impacts of wireless communication companies. Benchmarking: An International Journal, 15(3), 212-224. http://dx.doi.org/10.1108/14635770810876566

Levitt, B., \& March, J. G. (1988). Organizational learning. In W. R. Scott (Ed.), Annual review of sociology (pp. 319-340). Palo Alto, CA: Annual Reviews.

Lo, S., \& Lu, W. (2006). Does size matter? Finding the profitability and marketability benchmark of financial holding companies. Asia-Pacific Journal of Operational Research, 23, 229-246. http://dx.doi.org/10.1142/S0217595906000930

Lubatkin, M. (1983). Merger and the performance of acquiring firm. Academy of Management Review, 8, 
218-225.

Majumdar, S. (1998). On the utilization of resources: perspectives from the US telecommunications industry. $\begin{array}{lllr}\text { Strategic } & \text { Management } & \text { Journal, } & \text { 809-831. }\end{array}$ http://dx.doi.org/10.1002/(SICI)1097-0266(199809)19:9<809::AID-SMJ969>3.0.CO;2-U

Majumdar, S. K., Moussawi, R., \& Yaylacicegi, U. (2010). Is the efficiency doctrine valid? An evaluation of US local exchange telecommunications company mergers. Emerald Group Publishing Limited, 12(5), 23-41.

Majumdar, S., \& Chang, H. (1996). Scale efficiencies in US telecommunications: an empirical investigation. $\begin{array}{lllll}\text { Managerial and Decision } & \text { Economics, } & \text { 303-318. }\end{array}$ http://dx.doi.org/10.1002/(SICI)1099-1468(199605)17:3<303::AID-MDE753>3.0.CO;2-U

McDonald, J. (2009). Using least squares and tobit in second stage DEA efficiency analyses. European Journal of Operational Research, 197(2), 792-798. http://dx.doi.org/10.1016/j.ejor.2008.07.039

Min, H., \& Joo, S. (2006). Benchmarking the operational efficiency of third party logistics providers using data envelopment analysis. Supply Chain Management: An International Journal, 11(3), $259-265$. http://dx.doi.org/10.1108/13598540610662167

Mostafa, M. (2007). Benchmarking top Arab banks' efficiency through efficient frontier analysis. Industrial Management \& Data Systems, 107(6), 802-823. http://dx.doi.org/10.1108/02635570710758734

NRC Handelsblad. (2003, November 29). Ik zal het bolwerken, ik zal slagen [I w succeed].

Seth, A. (1990). Value creation in acquisitions: A re-examination of performance issues. Strategic Management Journal, 11, 99-115. http://dx.doi.org/10.1002/smj.4250110203

Singh, F., \& Mogla, M. (2008). Impact of mergers on profitability of acquiring companies. The Icfai University Press, 5(2), 60-76.

Sufian, F. (2004). The efficiency effects of bank mergers and acquisitions in a developing economy: Evidence from Malaysia. International Journal of Applied Econometrics and Quantitative Studies, 1(4), 53-74.

Sufian, F. (2006). Bank mergers \& acquisitions: A non-stochastic frontier window event study approach to analyze the effects on efficiency. The ICFAI Journal of Merger \& Acquisition, 3, 7-25.

Sufian, F., \& Habibullah, M. S. (2009). Assessing the impact of mergers and acquisitions on bank cost efficiency. Capital Markets Review, 17(1\&2), 21-42.

Thanassoulis, E. (1995). Assessing police forces in England and Wales using data envelopment analysis. European Journal of Operational $\quad$ Research, $641-657$. http://dx.doi.org/10.1016/0377-2217(95)00236-7

Uri, N. (2001). Measuring the impacts of price caps on productive efficiency in telecommunications in the United States. The Engineering Economics, 46(2), 81-113. http://dx.doi.org/10.1080/00137910108967564

Vera, A., \& Kuntz, L. (2007). Process-based organization design and hospital efficiency. Health Care Management Review, 32(1), 55-65. http://dx.doi.org/10.1097/00004010-200701000-00008

Wan Mahmood, W. M., \& Mohammad, R. (2007). Does operating performance really improve following mergers? The case of Malaysian banks. The Icfai Journal of Mergers \& Acquisitions, IV(3), 69-78.

Wooi, H. C., Khim, H. G., \& Masron, T. A. (2009). Financial efficiency of SMEs in the Northern Corridor Economic region: a DEA Analysis. Capital Market Review, 17(1\&2), 1-19.

Wu, S. (2008). Bank Mergers and Acquisitions- An Evaluation of the 'four pillars' policy in Australia. Australian Economic Paper, 47, 141-155. http://dx.doi.org/10.1111/j.1467-8454.2008.00337.x

Zhu, J. (2004). Imprecise DEA via standard linear DEA models with revisit to a Korean mobile telecommunication $\quad$ company. Operations $\quad$ Research, $\quad$ 52(2), http://dx.doi.org/10.1287/opre.1030.0072 